\title{
AUTORITARISMO E DEMOCRACIA NOS DISCURSOS DE PARLAMENTARES DO PSL NA CÂMARA DOS DEPUTADOS
}

AUTHORITARIANISM AND DEMOCRACY IN THE SPEECH OF PSL'S CONGRESSMEN IN BRAZILIAN CHAMBER OF DEPUTIES

Tayná Paolino

Doutoranda em Ciências Sociais pelo Programa de Pós-graduação em Ciências Sociais da Universidade Federal Rural do Rio de Janeiro (PPGCS/UFRRJ). Mestre em Ciência Política pelo Programa de Pós-graduação em Ciência Política da Universidade Federal do Estado do Rio de Janeiro (PPGCP/UNIRIO). Graduada em Ciência Política pela UNIRIO. Pesquisadora do Laboratório de Eleições, Partidos e Política Comparada (LAPPCOM), grupo vinculado à Universidade Federal do Rio de Janeiro (UFRJ) e à UFRRJ. É coordenadora do Projeto Fala Batan: O Jovem Protagonista, financiado pela Fiocruz, e pesquisadora da Viva Rio.

\section{Leonardo Puglia}

Jornalista formado pela Universidade do Estado do Rio de Janeiro (UERJ), pós-graduado em Gestão de Negócios pela Escola Superior de Propaganda e Marketing (ESPM-RJ), mestre e doutor em Ciências Sociais pela Pontifícia Universidade Católica do Rio de Janeiro (PUC-Rio). Pesquisador associado à International Gramsci Society do Brasil, dedicando-se ao estudo das direitas brasileiras em perspectiva histórica, com ênfase nas relações entre internet e política. Também é professor na Faculdade Católica Salesiana Maria Auxiliadora, diretor do Sindicato dos Professores de Macaé e Região, e sócio na agência Martelo Marketing. 


\section{RESUMO}

Este artigo tem o objetivo de contribuir com o debate sobre as direitas brasileiras identificando marcadores autoritários presentes nas falas de alguns dos principais deputados federais eleitos pelo Partido Social Liberal (PSL), em 20I8. Com base na análise dos discursos proferidos no plenário da Câmara, em 20I9, por Eduardo Bolsonaro, Joice Hasselmann, Delegado Waldir, Hélio Lopes e Carlos Jordy, identificam-se três tipos de representante políticos: o político autoritário, o político de direita tradicional e o político do bolsonarismo. A conclusão é que o PSL e a candidatura de Jair Bolsonaro conseguiram aglutinar diferentes perfis de representantes políticos de direita sob a égide do antipetismo, mas não demorou para que tensões internas viessem a público.

Palavras-chave: autoritarismo; PSL; direita; Câmara Federal.

\section{ABSTRACT}

This paper aims to contribute to the debate on Brazilian right wing by identifying authoritarian traces in the speeches of federal deputies elected by the PSL in 2018. Based on the analysis of the speeches given in the plenary of the Chamber in 2019 by Eduardo Bolsonaro, Joice Hasselmann, Delegado Waldir, Hélio Lopes and Carlos Jordy, we identified three types of political representatives: the authoritarian politician, the traditional right-wing politician, and the Bolsonarian politician. The conclusion is that the PSL and Jair Bolsonaro's candidacy managed to bring together different profiles of right-wing political representatives under the aegis of antipetismo, but it did not take long for internal tensions to become public.

Keywords: authoritarianism; PSL; right-wing; Federal Chamber. 


\section{Introdução}

Se a democracia moderna pressupõe a participação política, a garantia das liberdades individuais e a soberania do voto como características constitutivas, não é forçoso afirmar que foram escassos os períodos democráticos na história brasileira. Na verdade, os 33 anos comemorados em 202I fazem da Nova República o mais longo período democrático já experimentado pelo país.

Esse dado é relevante por si só, mas tem ganhado novo sentido diante das ameaças diárias às instituições democráticas, disparadas de dentro do Palácio do Planalto pelo próprio presidente da república, Jair Bolsonaro. O capitão reformado do Exército foi eleito em 20I8, após 30 anos de uma carreira política marcada pela apologia da ditadura militar, incluindo a exaltação de torturadores.

A vitória de Bolsonaro nas urnas, com 57,6 milhões de votos, deve ser compreendida num contexto histórico específico, marcado por uma escalada de criminalização da política impulsionada pela parceria entre a Operação Lava Jato e a grande mídia corporativa. Foi nesse momentum que as direitas ressurgiram como fenômeno de massa, mobilizando ferramentas de comunicação digital, sobretudo o Facebook, para promover as grandes manifestações de rua que pediram a derrubada da presidenta Dilma Rousseff, em 2015 e 2016.

Mais de 50 anos depois, cartazes anticomunistas citando Cuba voltavam às ruas ao lado de faixas em favor de uma intervenção militar que fechasse o Congresso Nacional e o Supremo Tribunal Federal (STF). O evidente paralelo com o processo de ruptura que levou ao fim do período democrático anterior, em 1964, acendeu o sinal de alerta entre os analistas sobre o comprometimento com a democracia da "nova direita". Essa nova direita que foi às ruas tornou-se um grande guarda-chuva de pautas antidemocráticas, punitivistas, neoliberais e neopentecostais, e venceu as eleições presidenciais de 2018.

Em seus três primeiros anos do governo, Jair Bolsonaro atuou diariamente para desestabilizar e subverter os pilares democráticos da República de I988, confirmando as previsões daqueles que enxergaram na carreira do capitão reformado do Exército todos os sinais apontados por Levitsky e Ziblatt (2018) para descrever um político autoritário.

Como num déjà vu sombrio, ainda que repleto de elementos farsescos, novamente os principais líderes do campo da direita brasileira atacavam a soberania do voto e as liberdades individuais com o objetivo de impor seus valores ao restante da sociedade. $\mathrm{Ou}$ seja, talvez a "nova direita" não fosse tão nova assim. É o questionamento que surge quando se compreende os impasses de hoje a luz da história do país, já que a tradição das direitas brasileiras é marcada pelo autoritarismo. Nesse sentido, um analista não pode 
perder de vista o peso do protagonismo conservador na política nacional se busca entender os sentidos do predomínio antidemocrático na história brasileira.

Um período autoritário não se sustenta sem algum enraizamento na sociedade. E essa capilaridade se estrutura não somente pela atuação de instituições como as Forças Armadas, os grandes veículos de mídia, as organizações religiosas e os grupos empresariais, mas também por meio de valores sociais legitimados e enraizados em setores expressivos da população. Daí a profundidade e a complexidade do fenômeno.

Este artigo tem o objetivo de contribuir para esse debate, analisando os discursos proferidos na Câmara Federal, em 20I9, por cinco parlamentares do Partido Social Liberal (PSL), partido que, em 20I8, elegeu o presidente da república e 52 deputados federais, muitos com primeiro mandato e formando a segunda maior bancada. Nas falas de Joice Hasselmann, Delegado Waldir, Eduardo Bolsonaro, Hélio Lopes e Carlos Jordy, identificam-se e articulam-se os elementos autoritários para compreender: o que permanece de antidemocrático nas direitas brasileiras; como esses traços autoritários podem unificar o campo direitista; e de que maneira essa marca deletéria para a democracia brasileira se renova e se adapta ao novo contexto histórico.

\section{A direita brasileira e suas relações com o autoritarismo}

Durante 2I anos, o Brasil foi governado por uma ditadura militar que mobilizou a retórica anticomunista como um eixo de sustentação capaz de unificar diferentes setores da sociedade - entre eles, empresários, grande mídia e segmentos da igreja católica - e que tinha como objetivo justificar a implementação e o aprofundamento do regime de exceção. A ditadura militar foi marcada pela supressão das eleições livres e das liberdades individuais, incluindo censura, tortura e assassinatos de opositores políticos.

O bloco formado em torno dos militares, em 1964, pela elite empresarial e por setores conservadores da política brasileira, só começou a rachar com a crise econômica provocada pelos choques do petróleo, na segunda metade da década de I970. Quando a ditadura se enfraqueceu, e o movimento social e cultural que pressionava pela anistia aos exilados e pela volta das eleições livres ganhou força e apoio na sociedade, o alto comando do regime militar implementou um projeto de abertura "lenta, gradual e segura" que permitiu que as liberdades individuais e políticas voltassem, finalmente, às mãos dos civis.

A redemocratização foi feita nos termos das forças armadas, garantindo a impunidade em relação às torturas e aos assassinatos praticados pelo alto comando, mas não deixou de ser resultado da pressão social provocada pela impopularidade crescente do regime militar, aprofundada pela hiperinflação e pela escalada da violência urbana. 
Nesse contexto histórico, a pesquisa realizada por Antônio Flávio Pierucci (1987) revelou que apenas 6\% dos deputados constituintes se identificavam como sendo "de direita" ou "centro-direita" (p. 38). Não que essa fosse a realidade política do Brasil, mas o final da ditadura militar desgastou a visão da sociedade sobre a direita, forçando esse campo político a se apresentar perante a sociedade com uma cara nova. Contudo, a vitória de um candidato de direita, Fernando Collor (PRN), num processo eleitoral - o primeiro em 29 anos - bastante polarizado com o candidato da esquerda, Lula (PT), mostrava que a díade direita-esquerda continuaria marcando as disputas seguintes na Nova República.

Esse constrangimento com a filiação política de direita que se revelara no fenômeno do "voto envergonhado" em Jânio e Maluf (PIERUCCI, 1987) iria se dissipar com o distanciamento temporal progressivo em relação à memória da ditadura militar e com a reorganização dos diferentes setores da direita em torno da oposição ao Partido dos Trabalhadores (PT), maior agremiação de esquerda da América Latina, que governaria o país de 2002 a 20I6. O fim se deu quando a presidenta Dilma Rousseff foi derrubada num processo de impeachment amplamente questionado do ponto de vista jurídico, mas sustentado nas ruas pelas maiores manifestações de direita registradas no Brasil desde A Marcha da Família com Deus pela Liberdade, que pressionara pela derrubada de João Goulart, em 1964 (PUGLIA, 2020).

Esse paralelo histórico seria reforçado, aos olhos dos analistas, pelo retorno estridente do anticomunismo nas manifestações, incluindo a presença massiva de cartazes e palavras de ordem em defesa de uma intervenção militar que colocasse fim à república democrática instituída em I988. Foi nesse contexto que surgiram inúmeros estudos buscando explicar, com base em diferentes perspectivas, o que seria essa "nova direita" brasileira. Em linhas gerais, continuaria sendo caracterizada pela união entre liberalismo econômico e conservadorismo moral de traço cristão, somada à defesa do punitivismo como única solução para a segurança pública, um traço identificado pioneiramente nas Ciências Sociais pela pesquisa realizada por Pierucci, em 1987, na cidade de São Paulo.

Se a oposição aos governos do PT serviu para unificar a ação de diferentes frações da direita, seu renascimento popular como fenômeno de massas, após cinco décadas, foi impulsionado pelo impacto causado na opinião pública pala cobertura midiática ostensiva e sensacionalista dos desdobramentos da Operação Lava Jato. Foi quando o sentimento de antipolítica, que havia se manifestado de modo abrupto e difuso nas Jornadas de Junho de 20I3, ganhou corpo e foi canalizado, de maneira eficaz, na derrubada de Dilma Rousseff. 
Assim como acontecera durante toda a República de 1946, quando a UDN mobilizou a retórica anticorrupção seguida por incursões golpistas - do suicídio de Vargas, em I954, até a derrubada de Jango dez anos depois -, a direita brasileira voltaria a mobilizar a pauta do combate à corrupção, com apoio ostensivo da grande mídia, como forma de ascender ao poder para implementar o programa neoliberal derrotado nas urnas em 2014.

O caldo cultural autoritário fermentado nesse processo histórico, no entanto, fugiria ao controle dessas elites políticas e empresariais, até porque partes dessas mesmas elites foram duramente impactadas pela Operação Lava Jato, vide o declínio dos resultados eleitorais do Partido da Social Democracia Brasileira (PSDB) e do Partido do Movimento Democrático Brasileiro (PMDB) (SANTOS, 2018). Entre outros motivos, o sentimento de antipolítica transbordou os limites desejados pela grande mídia corporativa, uma vez que esta não conseguia mais controlar as narrativas e os enquadramentos dos acontecimentos.

Isso porque uma revolução silenciosa vinha sendo gestada, desde os anos 1990, pela expansão da internet, e os atores políticos de direita revelaram-se hábeis no uso das ferramentas de comunicação digital (PATSCHIKI, 2OI2), especialmente o Facebook (SANTOS JUNIOR, 20I6). Eles as empregaram para difundir pautas e visões de mundo que incluíam um revisionismo histórico em relação à ditadura militar, fundamentado na reativação do espantalho comunista, agora encarnado pelo PT. Assim como o anticomunismo, em 1964, o antipetismo era um elemento capaz de articular os diferentes setores de direita numa ação política unificada (MESSENBERG, 20I7) e massiva, que pudesse influenciar amplos setores da sociedade brasileira.

A culminância desse movimento histórico parece ter acontecido nas eleições presidenciais de 20I8, quando o deputado federal Jair Bolsonaro (RJ), de longe o político mais popular da internet (MELLO, 2O2O), elegeu-se presidente encampando as principais pautas de direita (liberalismo econômico, conservadorismo moral e punitivismo), ao mesmo tempo que se apresentava como um outsider disposto a enfrentar, com base em uma retórica de exaltação da ditadura militar, um sistema político interpretado como corrupto em sua totalidade.

Por mais que essa narrativa não encontrasse nenhum respaldo real na trajetória de um político com 30 anos de carreira como parlamentar, Bolsonaro acabou sendo eleito com 57,8 milhões de votos e arrastou 52 deputados federais, fazendo do seu partido, o PSL, a segunda maior bancada do Congresso Nacional, atrás apenas do PT. O novo presidente acabaria se desfiliando do partido ainda no primeiro ano de governo, por não conseguir controlá-lo a seu gosto. Isso provocou uma divisão interna no PSL, entre aqueles que continuavam apoiando Bolsonaro e os parlamentares que se tornaram opositores, como Joice Hasselmann. 
Se o PSL já era relevante por ser o segundo maior partido da Câmara e por agrupar diferentes segmentos da direita que elegeram Bolsonaro, esse racha interno provocado pela saída do presidente tornou o partido um objeto de estudo ainda mais significativo para a compreensão das divisões no campo da direita, que haviam sido eclipsadas na unidade alcançada na luta contra o PT, mas se tornaram cada vez mais nítidas durante os três primeiros anos de governo Bolsonaro.

Ao analisar a diversidade que o compõe, pode-se compreender melhor o que caracteriza o campo da direita no Brasil. Esse é um dos objetivos do presente artigo, mas não seria possível empreender tal esforço de análise do cenário político contemporâneo sem levar em consideração as ameaças cotidianas do presidente à democracia brasileira e a força do discurso golpista autoritário nas suas bases de sustentação. Por isso, é preciso não apenas identificar os traços autoritários duradouros presentes nos principais discursos da direita brasileira, como também apontar, de maneira preliminar, alguns dos elementos capazes de unificá-los em momentos históricos como o de 1964 e 2016-2018.

A proposta aqui também envolve discutir como o velho autoritarismo das direitas brasileiras se renova para se adaptar à complexidade da realidade contemporânea. Sendo uma referência teórica importante o livro Como as democracias morrem, de Levitsky e Ziblatt (20I8). Este livro de política comparada se tornou rapidamente um best-seller mundial ao denunciar os riscos lançados diante das democracias liberais pela atuação de diversos líderes ao redor do mundo, como Donald Trump e Viktor Orbán, que, depois eleitos, passam a subverter processos e instituições democráticas com o objetivo de aumentar progressivamente seu poder.

Segundo Levitsky e Ziblatt (20I8, p. 34), são quatro os sinais de alerta que podem ajudar a reconhecer um autoritário:

Nós devemos nos preocupar quando políticos: I) rejeitam, em palavras ou ações, as regras democráticas do jogo; 2) negam a legitimidade de oponentes; 3) toleram e encorajam a violência; e 4) dão indicações de disposição para restringir liberdades civis de oponentes, inclusive a mídia.

De acordo com os autores norte-americanos, os outsiders populistas são políticos contra o establishment, que, "afirmando representar a 'voz do povo' entram em guerra contra o que descrevem como uma elite corrupta e conspiradora", denunciando que o sistema político e eleitoral foi sequestrado, corrompido e fraudado pela elite (LEVITSKY; ZIBLATT, 20I8). 
É preciso pontuar que o populismo, como muitas vezes Levitsky e Ziblatt tentam enquadrar em seu esquema, não é homogêneo e nem pode ser considerado como um todo autoritário. $\mathrm{O}$ autoritarismo e o atual conservadorismo têm contornos bem particulares, que serão discutidos no decorrer deste texto com base em elementos empíricos. Esse cuidado metodológico é importante, já que "populismo" segue sendo um conceito ambíguo nas Ciências Sociais, tendo sido utilizado recentemente para desconstruir experiências progressistas e democráticas do início do século XXI na América Latina.

Seria equivocado confundir essas experiências de inclusão social, ainda que tímidas, de setores historicamente marginalizados com o fenômeno mais recente de ascensão de um conservadorismo expressamente autoritário. Apesar de ser sustentado pelo voto, o populismo de direita se articula, sobretudo, por meio de instituições como a Igreja e as Forças Armadas, e recorre às novas tecnologias de comunicação digital, por exemplo, Facebook e WhatsApp, como principal meio de mobilização.

Por isso, optou-se por analisar a ascensão do conservadorismo autoritário - ou populismo de direita - em consonância com o que tem sido discutido nesse campo de estudos, pelo prisma da "nova direita", no âmbito nacional; ou da "direita radical", na esfera internacional. Como afirma Heywood (2010), essa nova direita "é como um casamento entre as duas tradições ideológicas aparentemente antagônicas. [...] que tenta unir o libertarismo econômico ao autoritarismo estatal e social. Como tal, é uma mistura de características radicais, reacionárias e tradicionais" (p. 97).

\section{Metodologia}

O PSL elegeu 52 deputados federais na eleição de 20I8, sendo quase metade desses parlamentares, 29 ao total, oriundos da região Sudeste do Brasil. ${ }^{1}$ O Sudeste é o maior colégio eleitoral brasileiro, com $43 \%$ do total de eleitores aptos a votar. ${ }^{2}$ Portanto, para compreender o fenômeno eleitoral do PSL, considera-se uma escolha oportuna trabalhar com a amostra de deputados federais da região Sudeste, tendo como foco Rio de Janeiro e São Paulo.

No atual estágio da literatura, existem três modos principais de se estudar elites políticas: o método posicional, o método decisional e o método reputacional (CODATO; PERISSINOTTO, 2OI5). Ao dialogar com as dinâmicas constitutivas do método posicional, analisa-se os indivíduos que ocuparam os espaços de mando formal na Câmara Federal,

\footnotetext{
${ }^{1}$ Disponível em: <https://istoe.com.br/sudeste-e-sul-concentram-75-da-bancada-eleita-do-psl/>. Acesso em: 31 ago. 2021.

${ }^{2}$ Disponível em: <https://odocumento.com.br/eleicoes-2020-conheca-os-maiores-colegios-eleitorais-do-pais-e-o-perfil-doeleitorado-brasileiro/>. Acesso em: 31 ago. 2021.
} 
sendo esses espaços identificados com base na compreensão da estrutura institucional do parlamento brasileiro.

Isso significa compreender que lideranças partidárias têm papel crucial dentro da nova ordem constitucional do país (FIGUEIREDO; LIMONGI, 200I). São os líderes que organizam a relação entre Executivo e Legislativo, têm prioridade de fala durante as sessões do plenário e influenciam, no colégio de líderes, as pautas do dia.

Para incluir a dimensão posicional desta pesquisa, optou-se por analisar falas dos deputados federais do PSL que ocuparam o espaço da liderança do partido e da liderança do bloco do governo, quais sejam: Joice Hasselmann, Delegado Waldir e Eduardo Bolsonaro. No entanto, esse recorte metodológico acaba deixando de fora representantes muito bem votados do estado do Rio de Janeiro. Daí a opção por incluir nos critérios de seleção dos parlamentares analisados o método reputacional. Apesar de ter sido idealizado por meio de uma metodologia etnográfica, o método reputacional foi empregado aqui quando se pensou no aspecto da mobilização de recursos de poder e na influência com base no prestígio pessoal socialmente reconhecido (CODATO; PERISSINOTTO, 2015). Sendo o voto um poderoso instrumento de demonstração de prestígio socialmente reconhecido, decidiu-se por incluir na presente análise os discursos dos deputados federais Hélio Lopes e Carlos Jordy, os dois mais bem votados do estado do Rio de Janeiro (ver Tabela I).

Definidos os métodos posicional e reputacional como critérios de escolha dos parlamentares analisados, é preciso ressaltar o significado dos discursos desses deputados no sentido político mais amplo. Pois se o ofício do político em um sistema democrático inclui buscar consenso, negociar, mediar conflitos, representar interesses, elaborar política e se opor às políticas dos outros; a atividade linguística é central na atuação política, pois todas estas são ações comunicativas em sua essência (BAILEY, 2004).

Em suma, parlamentos são instituições dedicadas à discussão política, ${ }^{3}$ e os discursos dos representantes devem ser compreendidos como expressão do campo de ideias e valores dos representados, ainda que os sentidos se manifestem de maneira dialógica e mediada.

${ }^{3}$ Talk, em inglês - conversa, fala, discussão. 
Tabela 1. Votação dos deputados federais do PSL analisados nesta pesquisa.

\begin{tabular}{|l|l|l|}
\hline Colocação & Parlamentar/estado da federação & Número de votos \\
\hline 10 & Eduardo Bolsonaro (SP) & 1.814 .443 \\
\hline 20 & Joice Hasselmann (SP) & 1.064 .047 \\
\hline 30 & Hélio Lopes (RJ) & 341.828 \\
\hline 40 & Delegado Waldir (GO) & 274.397 \\
\hline 50 & Carlos Jordy (RJ) & 202.717 \\
\hline
\end{tabular}

Fonte: Disponível em: <https://www.tse.jus.br/>. Acesso em 26 nov. 2021.

\section{Quem é quem dentro do PSL?}

\section{Eduardo Bolsonaro}

Eduardo Bolsonaro é o terceiro filho do presidente Jair Bolsonaro. Esse é um dos motivos de ter se tornado o deputado mais votado do Brasil. Eduardo nasceu na cidade do Rio de Janeiro, formou-se em direito pela Universidade Federal do Rio de Janeiro (UFRJ) e se tornou escrivão da Polícia Federal. Sua carreira na política começou em 2014, quando foi eleito para seu primeiro mandato como deputado federal, pelo Partido Social Cristão (PSC), com 82 mil votos. ${ }^{4}$ Quatro anos depois, Eduardo foi reeleito pelo PSL com uma votação 22 vezes maior: I,8 milhão de votos. Assim como o pai, Eduardo tem forte presença nas redes sociais, com mais de I milhão de seguidores no Twitter, e mais de 2 milhões no Facebook.

Uma das suas palavras mais proferidas no plenário da Câmara é "imprensa" (ver Figura I). Seu discurso tem sempre como objetivo se contrapor à imprensa tradicional, a quem acusa de difundir notícias falsas contra sua família e o governo de seu pai. Como pano de fundo de todos esses discursos, está um tipo de defesa da ideia da liberdade de expressão que não concebe qualquer forma de regulamentação do conteúdo difundido pelos meios de comunicação, principalmente as novas mídias digitais.

Em linhas gerais, seus discursos tentam defender a família Bolsonaro das inúmeras acusações de disparos de fake news em massa contra adversários, incluindo as denúncias que deram origem a inquéritos no STF. Segundo o deputado, todas essas acusações são caluniosas, com o único objetivo de cercear a liberdade de expressão para garantir que os grandes veículos de mídia profissional continuem como o espaço hegemônico de formação de opinião:

\footnotetext{
${ }^{4}$ Disponível em: <https://brasil.elpais.com/brasil/2014/10/07/politica/1412684374_628594.html>. Acesso em: 29 ago. 2021.
} 
Sabemos que vai acontecer uma censura deliberada para que nós voltemos a ser cordeiros e implorar para a imprensa um espacinho na Carta ao Leitor deles para fazer valer a nossa opinião. Mas hoje nós temos os nossos perfis e a liberdade de fazer isso quando nós bem entendermos, é só ter Internet e um smartphone [...] A mamata deles está acabando. Vocês estão vendo a redução dos investimentos do Governo Federal na imprensa tradicional, certamente eles vão ranger os dentes. Mas é para isso que o Jair Bolsonaro foi eleito. ${ }^{5}$

\section{Figura 1. Nuvem de Palavras Eduardo Bolsonaro.}

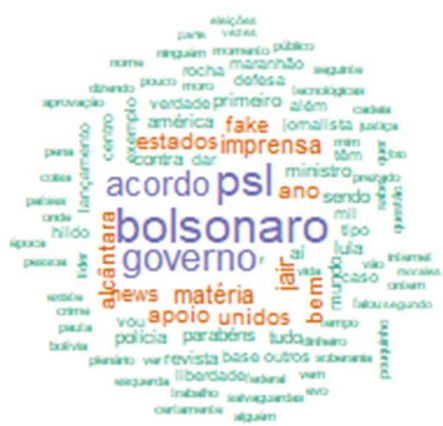

Fonte: Paolino (2020)

Outro aspecto a salientar de suas falas é a defesa feita por Eduardo Bolsonaro em relação às críticas ao rito democrático disparadas no Twitter por seu irmão, o vereador Carlos Bolsonaro, do Rio de Janeiro:

Não temos condições de mudar o Brasil na velocidade em que gostaríamos, Sra. Presidente. Por nós, a velocidade seria outra. Mas o tempo do Congresso não é o tempo da sociedade. Ponto! ${ }^{6}$

A defesa da política de liberação do acesso da população às armas de fogo é, por si só, inconstitucional, já que confronta dispositivos do Estatuto do Desarmamento aprovado em 2003, conforme julgou o STF em março de $202 \mathrm{I}^{\top}{ }^{\top}$ Contudo, o grande problema está nos apontamentos feitos por Eduardo Bolsonaro para justificar a liberação do armamento da população. Para ele, se "voltar um regime como o de Lula", a população precisa estar

\footnotetext{
${ }^{5}$ Discurso presente na página da Câmara de Deputados (www.camara.leg.br), sem revisão do orador. Acesso em: 31 ago. 2021.

${ }^{6}$ Discurso presente na página da Câmara de Deputados (www.camara.leg.br), sem revisão do orador. Acesso em: 31 ago. 2021.

${ }^{7}$ Discurso presente na página da Câmara de Deputados (www.camara.leg.br), sem revisão do orador. Acesso em: 28 ago. 2021.
} 
armada para que "não fiquemos sob os desmandos de um governo autoritário". ${ }^{8}$ O que significa isso, na prática, se não a resistência armada contra um governo eleito democraticamente?

\section{Joice Hasselmann}

Joice Hasselmann tem 4I anos e nasceu em Ponta Grossa, no estado do Paraná. Formada em jornalismo pelo Centro Universitário Santa Amélia (UniSecal), começou a carreira como radialista na rádio $\mathrm{CBN}$ e passou, nos anos seguintes, por grandes veículos de comunicação, como a rádio BandNews, a revista Veja e o jornal O Globo. Também foi uma participante ativa das manifestações pelo impeachment da presidenta Dilma Rousseff, tendo sido convidada pela advogada Janaína Paschoal a acompanhar o processo no Congresso Nacional. Joice tem mais de I milhão de seguidores no YouTube e 2 milhões no Facebook.

No início do ano de 20I9, a deputada ainda estava alinhada ao presidente Jair Bolsonaro em sua luta constante pela eliminação do inimigo em comum, o PT. Essa concepção não está muito distante da redução da política à distinção existencial entre amigos e inimigos teorizada por Carl Schmitt, em The concept of the political (2007).

Eu digo à V. Ex. ${ }^{a}$, Deputado, e à Oposição que a vida do PT não será fácil nesta Casa, porque nós vamos, sim, brigar pela prisão em segunda instância, e ela será aprovada nesta Casa. Eu vou dizer a V. Ex. ${ }^{a}$ que nós veremos Lula, chefe da quadrilha do Petrolão, apodrecer na cadeia. E este time aqui, do Presidente Jair Bolsonaro, está pronto para a luta. Aqui tem soldado, aqui tem guerreiro! Nós somos um time que vai fazer diferença neste País, e o PT não vai se criar mais nesta Nação. ${ }^{9}$

Ao analisar as falas da deputada no fim de 2019, sua insatisfação com os rumos do governo se torna explícita e começam a aparecer críticas abertas ao presidente Jair Bolsonaro e aos seus filhos. Essa mudança de postura tem como um dos motivos a disputa política sobre os rumos da liderança do PSL e os ataques pessoais misóginos que Joice Hasselmann passou a receber dos apoiadores da família Bolsonaro nas redes sociais. Em resposta aos ataques, a parlamentar fez um longo discurso no plenário da Câmara, recebendo a solidariedade de parlamentares da oposição.

Uma importante marca da atuação da deputada foi a defesa do liberalismo econômico, sobretudo durante os debates em torno da Reforma da Previdência. Do púlpito da Câmara, a

\footnotetext{
${ }^{8}$ Discurso presente na página da Câmara de Deputados (www.camara.leg.br), sem revisão do orador. Acesso em: 31 ago. 2021.

${ }^{9}$ Discurso presente na página da Câmara de Deputados (www.camara.leg.br), sem revisão do orador. Acesso em: 31 ago. 2021.
} 
parlamentar disse ser "absolutamente liberal na economia", defendeu a "austeridade fiscal" do governo e, por diversas vezes, pregou "a redução do Estado brasileiro" por meio da privatização do patrimônio da União (ver nuvem de palavras, Figura 2).

Figura 2. Nuvem de palavras Joice Hasselmann.

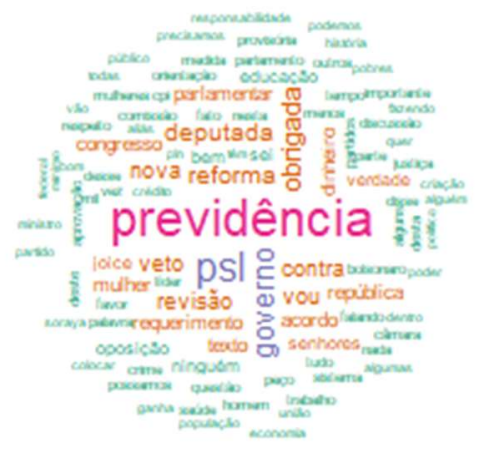

Fonte: Paolino (2020).

\section{Hélio Lopes}

Antes de concorrer à Câmara Federal com o mesmo número na urna que Eduardo Bolsonaro (I.720), e usando o sobrenome Bolsonaro, Hélio Lopes já havia sido candidato a vereador em 2004, no município de Queimados, no Rio de Janeiro, obtendo o total de 277 votos pelo Partido Republicano Progressista (PRP). ${ }^{10}$ Foi eleito, em 20I8, o deputado federal mais votado no estado do Rio de Janeiro, mas fez apenas dois discursos no plenário em seu primeiro ano de mandato, ambos focados na exaltação da figura de Jair Bolsonaro (ver nuvem de palavras na Figura 3) e em críticas aos governos do PT e do Partido Socialismo e Liberdade (PSOL).

Sua eleição com uma votação tão expressiva está relacionada ao poder de mobilização que a figura de Jair Bolsonaro teve no estado do Rio de Janeiro, sua base eleitoral, e principalmente na zona oeste da cidade:

Agradeço aos meus 345.234 eleitores, que há mais de 20 anos acompanham Jair Messias Bolsonaro e confiaram a mim a responsabilidade de representá-los aqui no Parlamento. Minha missão é combater a corrupção instituída pelo PT e considerada a maior da

\footnotetext{
${ }^{10}$ Disponível em: <http://www.fgv.br/cpdoc/acervo/dicionarios/verbete-biografico/helio-fernando-barbosa-lopes>. Acesso em: 29 ago. 2021.
} 
história do Brasil. É lutar incansavelmente pela segurança pública nacional, que, com o sacrifício da própria vida, defende a população e, dia após dia, é massacrada pelo PT e pelo PSOL. Vamos aqui defender a família, que tem que ser respeitada. A população foi à rua, pediu o impeachment da Dilma, o que graças a Deus aconteceu, e de forma democrática elegeu Jair Messias Bolsonaro Presidente da República. Meus amigos, hoje completam-se 5 meses daquele ato covarde: a tentativa de homicídio do candidato à Presidência da República. Quero saber quem mandou matar Jair Messias Bolsonaro, meu irmão de coração. Eu sei que ele é branco, sim. Eu sou preto. Sou daltônico, não enxergo diferença. A minha cor é o Brasil. Juntos vamos mudar este Brasil e colocá-lo no rumo que ele merece. Vamos dar suporte a Jair Messias Bolsonaro, que vai ser considerado o maior Presidente da História do Brasil. ${ }^{11}$

\section{Figura 3. Nuvem de Palavras Hélio Lopes.}

Fonte: Paolino (2020).

\section{Delegado Waldir}

Delegado Waldir é natural do Paraná e, após passar no concurso da Polícia Civil, mudou-se para o estado de Goiás. Candidatou-se pela primeira vez pelo PSDB, em 20Io, e acabou ficando como suplente. Foi eleito em 2014 e 20I8, nas duas vezes como deputado federal mais votado do estado de Goiás. Em 20I4, se elegeu pelo Partido Republicano(PR) e, em 2018, pelo PSL, apoiando a candidatura de Jair Bolsonaro à Presidência.

Na nuvem de palavras (Figura 4), observa-se que PSL é o termo mais mencionado pelo deputado em seus discursos. Isso porque ele protagonizou diversos conflitos políticos com Joice Hasselmann e Eduardo Bolsonaro na disputa pela liderança do partido.

\footnotetext{
${ }^{11}$ Discurso presente na página da Câmara de Deputados (www.camara.leg.br), sem revisão do orador. Acesso em: 31 ago. 2021.
} 
O parlamentar também atuou em defesa da Reforma da Previdência, ainda que sua defesa do liberalismo econômico fosse mais tímida e superficial do que a de Joice Hasselmann. As afirmações do Delegado Waldir sobre o tema ficaram restritas a elogios ao caráter "liberal" do então presidente da Câmara, Rodrigo Maia, e à preocupação constante com o impacto das ações do parlamento na cotação da Bolsa de Valores.

Figura 4. Nuvem de Palavras Delegado Waldir.

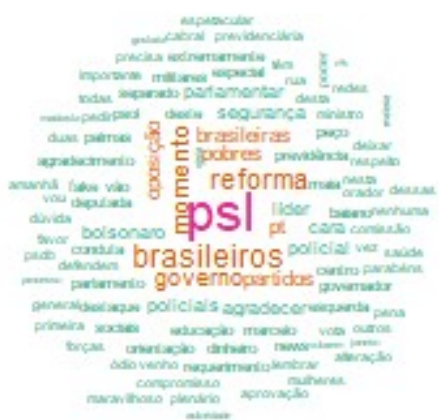

Fonte: Paolino (2020).

\section{Carlos Jordy}

Como ele mesmo se define, Carlos Jordy é "nascido e criado em Niterói". ${ }^{12}$ Cursou Turismo e Hotelaria e foi servidor público da cidade de São Gonçalo, vizinha de Niterói, como Analista de Planejamento e Orçamento da Prefeitura. Atualmente, é analista na área de licitações e contratos da Agência Nacional de Transportes Aquaviário. Sua participação política começou em 20I6, quando se elegeu vereador dizendo-se representante dos ideais de Jair Bolsonaro na Câmara Municipal de Niterói. Protagonizou conflitos com movimentos sociais e o corpo docente e discente da Universidade Federal Fluminense (UFF) durante as manifestações contra o governo de Michel Temer. Jordy se define como um militante pelo fim da "dominação marxista" nas escolas e universidades (ver nuvem de palavras, na Figura 5).

Desde o início de sua carreira política, em 2016, quando foi eleito vereador em Niterói, Carlos Jordy já se alinhava abertamente às concepções mais extremistas do então deputado federal Jair Bolsonaro, como a comemoração do Golpe de i964:

\footnotetext{
${ }^{12}$ Disponível em: <https://www.carlosjordy.com.br/biografia>. Acesso em: 31 ago. 2021.
} 
Presidente, eu gostaria de parabenizar o Presidente Jair Bolsonaro por retomar as comemorações da contrarrevolução de 3I de março de I964, um momento em que o Brasil passava pela ameaça comunista, em que se tentou implantar, neste país, a ditadura do proletariado, financiados pela União Soviética e treinados em Cuba. Naquele momento, a população foi às ruas pedir que Jango fosse retirado da Presidência. Graças aos militares, hoje, nós não somos um Cubão. Viva os Militares! Viva o 3I de março! !3 $^{13}$

Figura 5. Nuvem de Palavras Carlos Jordy.

Fonte: Paolino (2020)

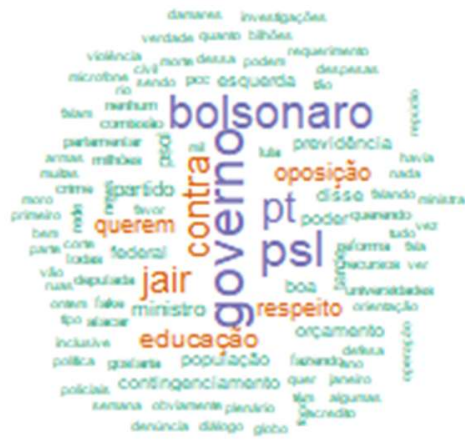

Defendendo uma concepção repressora da sociedade e justificando sua atuação a partir do que seria o desejo da maioria da população brasileira, Carlos Jordy retomou debates sobre projetos rejeitados no Congresso Nacional, como o que propõe a redução da maioridade penal:

Esse sujeito foi considerado inimputável porque nossa legislação é benéfica com menores de idade. Hoje ele volta ao noticiário por ter liderado uma rebelião num centro de saúde em São Paulo. Esse cidadão, que deveria apodrecer na cadeia, continua num spa, curtindo suas férias eternas e delinquindo. Acredito que é hora de este Parlamento ter a coragem de avançar num pleito da sociedade, que na esmagadora maioria é a favor da redução da maioridade penal. Devemos, sim, considerar este tema uma prioridade, já que é uma prioridade da nossa sociedade atual. ${ }^{14}$

\footnotetext{
${ }^{13}$ Discurso presente na página da Câmara de Deputados (www.camara.leg.br), sem revisão do orador. Acesso em: 31 ago. 2021.

14 Discurso presente na página da Câmara de Deputados (www.camara.leg.br), sem revisão do orador. Acesso em: 31 ago. 2021.
} 
Jordy também subiu ao plenário para endossar a opinião do presidente Bolsonaro de que se o Brasil vivenciasse manifestações como as que estavam ocorrendo no Chile, em 2019, seria necessário coibi-las com repressão:

Sr. Presidente, nós temos visto uma série de protestos no Chile, os quais desencadearam uma verdadeira onda de barbárie, de vandalismo. Ora, quem estaria por trás dessa onda de violência e de vandalismo? Os partidos de esquerda, que estão insatisfeitos com a retomada do poder na América Latina pela Direita, pelos conservadores. Sr. Presidente, há Deputados e Senadores que estão incitando esse tipo de violência aqui no Brasil. Digo a V. Ex. ${ }^{\text {a }}$ o Brasil não é o Chile. O Governo Bolsonaro não é um governo omisso, como foram os governos anteriores. Não se atrevam! O Governo Bolsonaro está disposto a usar as Forças Armadas para reprimir qualquer tipo de violência, vandalismo ou barbárie que possa colocar a ordem pública em perigo. ${ }^{15}$

O parlamentar também é a favor do armamento da população e nega que exista uma violência estrutural contra a população negra no Brasil:

Sr. Presidente, a Deputada que me antecedeu disse que nós defendemos armamento e eles, não. Engraçado é que há um vídeo em que ela fala que quer fazer um derramamento de sangue, que sem derramamento de sangue não há redenção. Eu queria saber como será feito esse derramamento de sangue? Sem armas? É isso o que eles querem? Na verdade, eles não defendem o armamento da população para o cidadão de bem, mas, sim, para todos os asseclas deles e para os traficantes. Quanto ao Deputado Coronel Tadeu, eu gostaria de parabenizá-lo por essa atitude, que foi uma afronta contra as instituições policiais... (Apupos.) Queremos ver é a polícia matar bandido, independentemente de cor. (Tumulto no plenário.) Se for negro... ${ }^{16}$

\section{Considerações finais}

Entre os deputados federais eleitos pelo PSL, nota-se três tipos de representantes políticos, sendo um dominante.

O primeiro tipo é o político do perfil autoritário, identificado segundo as quatro características descritas por Levitsky e Ziblatt (20I8): rejeição às regras democráticas;

\footnotetext{
${ }^{15}$ Discurso presente na página da Câmara de Deputados (www.camara.leg.br), sem revisão do orador.Acesso em: 31 ago. 2021.

${ }^{16}$ Discurso presente na página da Câmara de Deputados (www.camara.leg.br), sem revisão do orador.Acesso em: 31 ago. 2021.
} 
negação da legitimidade dos oponentes; estímulo à violência; e disposição para restringir liberdades civis. Esses marcadores são identificados de maneira mais explícita nas falas de Eduardo Bolsonaro e Carlos Jordy (ver Figuras i e 5). Ambos defendem abertamente a ditadura militar e o armamento da população para uma guerra civil contra governos adversários. Também atacam profissionais de imprensa e defendem políticas de segurança pública que aprofundem o extermínio sistemático de jovens negros, usando como argumento o discurso chavão "bandido bom é bandido morto".

O segundo tipo seria um representante de direita de perfil mais clássico, que defende medidas neoliberais na economia, além de algumas medidas autoritárias, como a prisão em segunda instância, ainda que estas não sejam o centro nem de sua prática, nem de sua retórica política. Entre os parlamentares aqui analisados, encaixam-se nesse perfil Joice Hasselmann, jornalista que se projetou no antipetismo, e Delegado Waldir, parlamentar oriundo do setor de segurança pública que havia feito carreira política antes da ascensão do bolsonarismo.

Já o terceiro tipo é o político inexpressivo, que pegou carona no fenômeno eleitoral do bolsonarismo. Similar a boa parte dos seus colegas de partido, Hélio Lopes foi eleito com fraca base de sustentação e sem ter relevante experiência política anterior. Esse perfil ajuda a explicar a atuação tímida do parlamentar, que fez apenas dois discursos em seu primeiro ano na Câmara Federal, ambos dedicados exclusivamente a exaltar a figura do presidente da república em oposição aos inimigos da nação: PT e PSOL, dois partidos de esquerda pintados em cores demonizadas. Por sua escassez e superficialidade, os discursos de Hélio Lopes podem parecer menos relevantes, mas é neles que se encontram alguns elementoschave para a compreensão da popularidade e da resiliência do bolsonarismo na sociedade, mesmo diante da acelerada degradação da vida do povo brasileiro.

O discurso schmittiano de Hélio Lopes simplifica e torna a política compreensível para amplos setores da população, ao mesmo tempo que mobiliza emocionalmente as bases de apoio do presidente e encobre os impactos nocivos das políticas bolsonaristas sobre o povo negro. Como homem negro e periférico, Hélio Lopes serve de ponte do povo para um governo essencialmente impopular, a poiado pela fração mais reacionária da elite rentista representada pela figura do ministro da economia Paulo Guedes.

Nesse sentido, a atuação de Carlos Jordy e Eduardo Bolsonaro é complementar à de Hélio Lopes, já que visa radicalizar as bases populares do bolsonarismo até que uma ruptura violenta da ordem democrática se torne viável, realizando, finalmente, o sonho da vida de Jair Bolsonaro: dar um golpe para restaurar uma ditadura militar de direita no Brasil.

Delegado Waldir e Joice Hasselmann, por outro lado, atuaram de maneira mais moderada e institucional, buscando trabalhar pela governabilidade da gestão Bolsonaro 
com o objetivo de implementar o programa neoliberal por meio dos ritos institucionais. $\mathrm{O}$ que, no caso de Hasselmann, colocou a parlamentar por São Paulo em rota de colisão com o núcleo duro do bolsonarismo, que é expressamente autoritário e antidemocrático, além de misógino, conforme comprovou a natureza do linchamento virtual promovido nas redes sociais.

A família Bolsonaro vai além do conservadorismo. Ela faz parte de uma ala reacionária da direita brasileira, já que seu objetivo é instalar um regime autoritário capaz de reverter os avanços democráticos conquistados pela Nova República, levando radicalmente a sociedade brasileira em direção a uma utopia que idealiza a violência de Estado que caracterizou os $2 \mathrm{I}$ anos de ditadura militar no Brasil.

Aqui se coloca uma linha que separa a direita abertamente autoritária e a direita democrática, que defende a democracia liberal. E essa linha se torna cada vez mais nítida à medida que Bolsonaro aprofunda o tensionamento com as instituições, sobretudo o STF, em busca de uma ruptura golpista.

Historicamente foi a retórica da ameaça comunista o elemento capaz de articular todo o campo da direita numa ação unificada, podendo a relação entre antipetismo e o fenômeno da nova direita ser lido nessa chave de interpretação. Mas como essa retórica tende a perder força quando a esquerda está na oposição, é natural que a unidade se enfraqueça e tensões e divisões dentro do campo da direita venham à tona.

Isso foi visto nos primeiros três anos do governo Bolsonaro, que de tão inábil, sobretudo na condução da pandemia, que vitimou mais de 600 mil pessoas no Brasil, tem colocado o PT, na figura de Lula, como favorito à corrida presidencial de 2022. Resta saber se a reativação do espantalho vermelho pode novamente unificar o campo da direita ou se a radicalidade crescente do golpismo bolsonarista acabou inviabilizando momentaneamente essa unidade, ao menos em torno do seu nome.

\section{Referências}

BAYLEY, P. The whys and wherefores of analysing parliamentary discourse. In: Cross-Cultural

Perspectives on Parliamentary Discourse. Amsterdam: John Benjamins Publishing Company, 2004. p. I-44.

CODATO, A.; PERISSINOTTO, R. Como estudar elites. Curitiba: Editora UFPR, 2015.

FIGUEIREDO, A.; LIMONGI, F. Executivo e Legislativo na nova ordem constitucional. Rio de Janeiro:

Editora FGV, 200I.

HEYWOOD, A. Ideologias políticas: do liberalismo ao fascismo. São Paulo: Ática, 20IO. 1 v. 
LEVITSKY, S.; ZIBLATT, D. Como as democracias morrem. Rio de Janeiro: Zahar, 2018.

MELLO, P. C. A máquina do ódio: notas de uma repórter sobre fake news e violência digital. São Paulo: Companhia das Letras, $202 \mathrm{O}$.

MESSENBERG, D. A direita que saiu do armário: a cosmovisão dos formadores de opinião dos manifestantes de direita brasileiros. Revista Sociedade e Estado, v. 32, n. 3, set./dez. 2017.

PAOLINO, T. Os mais votados do Brasil: discurso e ideologia na Câmara dos Deputados. 2020. 2 I4 f. Dissertação(Mestrado) - Centro de Ciências Jurídicas e Políticas, Universidade Federal do Estado do Rio de Janeiro, Rio de Janeiro, 2020.

PATSCHIKI, L. Os litores da nossa burguesia: o Mídia Sem Máscara em atuação partidária (200220II). 20I2. 419 f. Dissertação(Mestrado) - Programa de Pós-graduação História, Poder e Práticas Sociais, Universidade Estadual do Oeste do Paraná, Marechal Cândido Rondon, 2012.

PIERUCCI, A. F. As bases da nova direita. Novos Estudos CEBRAP, n. 19, p. 26-45, dez. 1987.

PUGLIA, L. Reação conectada: as direitas brasileiras em perspectiva histórica. Rio de Janeiro, 2020. 313 f. Tese (Doutorado) - Departamento de Ciências Sociais, Pontifícia Universidade Católica do Rio de Janeiro, Rio de Janeiro, 2020.

SANTOS JUNIOR, M. A. Vai pra Cuba!!! A rede antipetista na eleição de 20I4. 2016. I99 f. Dissertação (Mestrado) - Instituto de Arte e Comunicação Social, Universidade Federal Fluminense, Niterói, 2016.

SANTOS, F.; TANSCHEIT, T. Quando velhos atores saem de cena: a ascensão da nova direita política no Brasil. Colombia Internacional, n. 99, p. I5I-I86, 2018. Disponível em: <https://doi.org/I0.7440/colombiaint99.2019.06>. Acesso em: 22 jul. 2019.

SCHMITT, C. The concept of the political - expanded edition. Chicago; London: The University of Chicago Press, 2007. 